\title{
Interactive vs. non-interactive knowledge production by faculty members
}

\begin{abstract}
In this article we develop a model of individual choice to study the determinants of faculty members allocation of effort between interactive and non interactive activities. This model is tested by using censored and discrete choice econometric models to estimate optimum effort allocated to interactive activities and real interaction. We conclude, first, that individual responds to non-monetary rather than monetary incentives and to the difficulty of producing non-interactive rather than interactive knowledge. Second, we detect the possible existence of rationing, since optimum effort and real interaction depend on different variables.
\end{abstract}

\section{Introduction}

The importance of increasing university-industry interaction (UII) in most developed Western economies motivates this research. UII takes place in the form of contract and collaborative research, industry-oriented student's curricula, practices for students in firms, consultancy, joint centres, scientist exchange, informal contacts, seminars for firms, patent licensing, etc. The reasons behind this growth of UII lie in the enhancement of technological innovation attributed to a more tangible orientation of academic activities.

Within innovation studies, several approaches have come to justify the interweaving of universities in the economy: Freeman (1987) and Lundvall (1988) under the perspective of national systems of innovation, Gibbons et al. (1994) with their detection of new Mode 2 of knowledge production, Etzkowitz and Leydesdorff (1996) with their ideas about the Triple Helix model, Clark (1998) and his paradigm of an entrepreneurial university, etc. These approaches differ in the importance granted to universities in the innovation process, but do not question that some degree of interaction with firms should exist.

Other voices have been more critical. The economics of science approach recovers the Mertonian ideas that the mechanism of review by peers can efficiently assign R\&D resources 
(Dasgupta and David, 1994). It also emphasises that the promotion of UII responds to a narrow vision of the benefits of basic research, which leaves aside less tangible but equally beneficial links with innovation (David et al., 1994). Some of these benefits are increasing useful knowledge, training skilled graduates, creating new scientific instrumentation and methodology, forming networks and social interaction, increasing the capacity for scientific and technological problemsolving, creating new firms (Salter and Martin, 2001), providing social knowledge and access to unique facilities (Scott et al., 2002).

The former conflicting views set an ongoing debate on whether the marginal value of interactive activities by universities is higher than the marginal value of non-interactive activities or vice versa. At least in public universities, faculty members are autonomous to decide whether to engage on interactive activities or not. The aim of this paper is to analyse the effort they allocate between interactive and non-interactive activities. What are the motivations behind faculty members' behaviour? Do monetary incentives matter more than non-monetary ones? Is it important that production of interactive knowledge may be less time-consuming than of noninteractive one?

\section{Theoretical model}

In order to study the professor interactive activities, we develop a model of individual choice in which a maximising utility agent allocates his scarce time between interactive and non-interactive activities. We consider an activity interactive when it involves a relationship with industrial partners outside the university and non-interactive in the opposite case ${ }^{1}$. This classification overlaps with the usual distinction among academic R\&D and teaching (Euwals and Ward, 2005) since both interactive and non-interactive activities may include these tasks.

This approach draws from previous models by Beath et al. (2003) and Jensen and Thursby (2004). A difference with our model is that we do not introduce faculty members' time devoted to research in the utility function but faculty members' research output. Furthermore, we do not assume the distinction between basic research leading to prestige and applied research as a source

\footnotetext{
${ }^{1}$ Interaction with non-industrial partners falls into the category of "non-interactive activities", e.g. cooperation with other academic colleagues.
} 
of income, but between non-interactive and interactive activities, both of them leading to prestige and the former also as a source of income. ${ }^{2}$

We assume that the representative university professor -considered rational from an economic point of view- maximises the utility function defined by equation (1). Professor's utility level depends on two arguments: income (Y) and subjective prestige (M) that comes out of academic activities.

$$
\mathrm{U}=\mathrm{M}^{\mathrm{e}} \mathrm{Y}^{1-\mathrm{e}}
$$

Being $e$ a parameter with $\quad 0<e<1$

Notice that our notion of prestige is broader than the usual one, since we do not only refer to prestige stemming out from peer-review mechanisms but also from public image and social reputation, e.g. entering extra-academic networks, receiving gratitude from others or attention by mass-media, etc.

Therefore, subjective prestige, $\mathrm{M}$, derives from two sources: the results of interactive and noninteractive activities. We assume that $\mathrm{M}$ is obtained as a weighted average of each type of contribution.

$$
\mathrm{M}=\delta \mathrm{K}_{\mathrm{t}}+(1-\delta) \mathrm{K}_{\mathrm{n}}
$$

Where

$\mathrm{K}_{\mathrm{t}}-$ Professor contribution to knowledge from interactive activities.

$K_{n}-$ Professor contribution to knowledge from non-interactive activities.

$\delta$ - Parameter; $0 \leq \delta \leq 1$

With regards to individual income, it may be broken down in wage and revenue from the output of interactive activities, both given. Therefore

$$
\mathrm{Y}=\mathrm{W}+\mathrm{Q} \mathrm{K}_{\mathrm{t}}
$$

Where

w - Professor wage

\footnotetext{
${ }^{2}$ Finally, we do not consider a principal-agent model as Jensen and Thusby but an individual choice model as Beath et al., since it fits better in the European context, where, in most countries, universities and professors do not have so much bargaining power. In fact, wage levels at public universities are set by law.
} 
Q - Net revenue from a unit of knowledge coming from interactive activities.

Knowledge outputs, both interactive and non-interactive, are determined as linear functions of total time allocated in each activity.

$$
\begin{aligned}
& \mathrm{K}_{\mathrm{t}}=\mathrm{AT} \\
& \mathrm{K}_{\mathrm{n}}=\mathrm{B} \mathrm{N}
\end{aligned}
$$

Where

$\mathrm{T}$ - Time allocated by the professor to interactive activities

$\mathrm{N}$ - Time allocated by the professor to non-interactive activities

A, B - parameters

We normalise professor total time available to interactive and non-interactive activities to one. Therefore, the time constraint for professor will reduce to

$$
1=\mathrm{T}+\mathrm{N}
$$

Substituting equations 2 to 6 into equation 1, utility can be expressed as a function of the amount of time devoted to interactive activities $(\mathrm{T})$, being $\mathrm{T}$ the only decision variable,

$$
\mathrm{U}=[(1-\delta) \mathrm{B}(1-\mathrm{T})+\delta \mathrm{AT}]^{\mathrm{e}}(\mathrm{w}+\mathrm{QAT})^{1-\mathrm{e}}
$$

By maximising the latter expression with respect to $\mathrm{T}$, we obtain the following first order condition that is the result of the professor's optimisation problem:

$$
\mathrm{T}=\frac{\mathrm{QA}(1-\delta) \mathrm{B}(1-\mathrm{e})-\mathrm{w}[(1-\delta) \mathrm{B}-\delta \mathrm{A}] \mathrm{e}}{\mathrm{QA}[(1-\delta) \mathrm{B}-\delta \mathrm{A}]}
$$

Therefore, optimum time allocated to interactive activities only depends on the parameters of the model. Now, considering that $\mathrm{T}$ must lie between 0 and 1 , we can define $\mathrm{T}^{*}$ such that individual chooses

$$
\begin{aligned}
& T^{*}=0 \text { if } T<0 \\
& T^{*}=T \text { if } 0 \leq T \leq 1 \\
& T^{*}=1 \text { if } T>1
\end{aligned}
$$

The condition for an internal solution, i.e. for $0<\mathrm{T}<1$, is:

$$
\frac{(1-e) Q A(1-\delta) B}{Q A+w e}<(1-\delta) B-\delta A<\frac{(1-e) Q A(1-\delta) B}{w e}
$$

We can rewrite it this way: 


$$
\frac{(1-e) Q A}{Q A+w e}<1-\frac{\delta A}{(1-\delta) B}<\frac{(1-e) Q A}{w e}
$$

One necessary condition for this former to be met is that

$$
(1-\delta) B>\delta A
$$

In other words, the contribution to prestige of one unit of time devoted to non-interactive activities $(1-\delta) \mathrm{B}$ must be higher than the correspondent contribution from one unit of time in interactive activities $(\delta \mathrm{A})$. This is easy to understand: since interactive activities provide income, the individual would devote the totality of his time to these activities if the contribution to prestige of one unit of time devoted to these activities were equal or higher. Moreover, the difference between these two terms must be enough as to compensate the income received. This minimum difference depends on the income the individual can obtain from a unit of time devoted to interactive activities (QA) and the relative preference for income in the utility function (1-e). On the other hand, the value of this difference has also a maximum. Were the difference too high, the individual would concentrate all his time in non-interactive activities.

To ensure that the solution in equation (8) corresponds to a maximum, we obtain the second order condition of this problem, which corresponds to the following equation

$$
\begin{aligned}
& \frac{\partial^{2} U}{\partial T^{2}}=-[\partial A T+(1-\delta) B(1-T)]^{e}(w+A Q T)^{1-e} \bullet \\
& \left\{\frac{e(1-e)[\partial A-(1-\delta) B]^{2}}{[\delta A T+(1-\delta) B(1-T)]^{2}}+\frac{e(1-e)(Q A)^{2}}{(w+Q A T)^{2}}+\frac{2 e(1-e) Q A[(1-\delta) B-\delta A]}{[\delta A T+(1-\delta) B(1-T)](w+Q A T)}\right\}<0
\end{aligned}
$$

Considering that an interior solution holds and differentiating (8), we obtain a comparative statics exercise:

$$
\begin{gathered}
\frac{\mathrm{d} \mathrm{T}}{\mathrm{d} w}=\frac{-\mathrm{e}}{\mathrm{QA}}<0 \\
\frac{\mathrm{d} \mathrm{T}}{\mathrm{dQ}}=\frac{\mathrm{w} \mathrm{e}}{\mathrm{Q}^{2} \mathrm{~A}}>0 \\
\frac{\mathrm{d} \mathrm{T}}{\mathrm{d} \delta}=\frac{(1-\mathrm{e}) \mathrm{BA}}{[\delta \mathrm{A}-(1-\delta) \mathrm{B}]^{2}}>0 \\
\frac{\mathrm{d} \mathrm{T}}{\mathrm{dA}}=\frac{(1-\delta)(1-\mathrm{e}) \mathrm{Q}^{2} \mathrm{~A}^{2} \delta+\mathrm{we} \mathrm{Q}[\delta \mathrm{A}-(1-\delta) \mathrm{B}]^{2}}{\{\mathrm{QA}[\delta \mathrm{A}-(1-\delta) \mathrm{B}]\}^{2}}>0 \\
\frac{\mathrm{d} \mathrm{T}}{\mathrm{dB}}=\frac{-(1-\delta)(1-\mathrm{e}) \delta \mathrm{A}}{[\delta \mathrm{A}-(1-\delta) \mathrm{B}]^{2}}<0
\end{gathered}
$$




$$
\frac{\mathrm{d} \mathrm{T}}{\mathrm{de}}=-\left[\frac{\mathrm{QA}(1-\delta) \mathrm{B}+\mathrm{w}[(1-\delta) B-\delta \mathrm{A}]}{\mathrm{QA}[(1-\delta) \mathrm{B}-\delta \mathrm{A}]}\right]<0
$$

We conclude that the individual will decide to allocate more time to interactive activities the higher revenue from a unit of knowledge from interactive activities $(\mathrm{Q})$, the weight given to noninteractive activities in the determination of prestige $(\delta)$ and the amount of interactive knowledge produced by a unit of time devoted to such activity (A). On the other hand, the individual will be more reluctant to allocate time in interactive activities the higher his wage (w), the amount of noninteractive knowledge produced by a unit of time devoted to such activity (B) and the relative preference for prestige versus income (e).

\section{Results}

In order to estimate the former model, we use data on faculty members from the Valencian Community, gathered through a survey carried out in 2001. The Valencian Community is a Spanish region, with a per capita GDP about the national average. Its manufacturing structure relies on traditional, low-tech sectors such as toys, textile, shoes, furniture, ceramic tiles, etc. This pattern of specialisation is one of the reasons why the region has several technological weaknesses as for example a low level of expenditure on R\&D ( $0.81 \%$ of GDP in $2002,79 \%$ of the Spanish average and $42 \%$ of EU-15 average) mainly on the part of firms (that financed $32 \%$ of total R\&D in $2001,65 \%$ of the Spanish average and $54 \%$ of EU-15 average), a shortage of financial organisations of innovation, and little articulation of institutional links (Fernandez et al., 2001). Therefore, it fits in the description of a region with low absorptive capacity, and we will have to consider it in the interpretation of the results ${ }^{3}$, since universities produce economic effects on the local economy (Bleaney et al, 1992).

The population of the survey includes faculty members from the five public universities of the Valencian Community. We stratified it in three teaching scales: full professors, assistant professors

\footnotetext{
${ }^{3}$ We follow Cohen and Levinthal's (1990) definition of absorptive capacity: "a limit to the rate or quantity of scientific or technological information that firm can absorb". To justify the extension of the concept of absorptive capacity from firms to regions, see Niosi and Bellon (2002).
} 
and associate professors ${ }^{4}$. Selection was by means of simple random sampling. The sample was $10 \%$ of the population, or 872 individuals ${ }^{5}$. We obtained a response rate of $44 \%$, so we could build a database with 382 observations.

As the questionnaire was not designed to match our theoretical model, we had to build some proxies departing from the existing information. The questionnaire included questions regarding the support for different objectives of UII, which we will use as a proxy for the optimum effort allocated to interactive activities (see appendix). As the optimum effort allocated to interactive activities may not coincide with the degree of real interaction (i.e. if exogenous constraints or rationing on individual behaviour arises), it would result in a degree of real interaction below the individual optimum. Consequently, we define another variable as a proxy for the real effort allocated to interactive activities (see appendix).

Table 2 contains the estimation results of our proxy variable for the optimum time allocated to interactive activities, the average support for the objectives of UII. The significance of the $\sigma$ parameter across all columns indicates that there is actually censoring, thus the technique of estimation appears to be adequate. Column 1 is a base model with all the variables. We find that the intensity of the support for the objectives of UII depends positively on weight of interactive activities in the determination of prestige. Other coefficients do not have any significant effects, although their signs are as predicted by the theoretical model. For wage (w) and knowledge contribution by unit of time allocated to non-interactive activities (B) are correlated, we estimate separate regressions in Columns 2 and 3. When we remove one of the variables, the other one becomes significant, both with the expected negative sign. However, variable B shows a higher significant effect than w. Furthermore, when we follow a selection strategy to reduce the base model in column 1 to a model with significant variables only, w drops while B stands, as we can

${ }^{4}$ The equivalence between the Spanish original categories and the three categories that we mention is not exact, but it uses more popular terms, it simplifies the exposition at the same time that captures the intuition behind the original categories.

${ }^{5}$ The questionnaire was sent by the research vice-rectorates of each university by electronic mail to the random sample of faculty members. Once filled in, faculty members could return the questionnaire by electronic mail, ordinary mail or fax. After a first stage of spontaneous response, a follow-up team was organised to make telephone contact with faculty members of the sample. This fieldwork took place between $22^{\text {nd }}$ May 2001 and 30 June 2001. 
see in column 4. Therefore, B appears to reflect better the rationale of our model. In any case, the intensity of the support for the objectives of UII does not depend on income from interactive activities, knowledge contribution by unit of time allocated to interactive activities and parameters of the utility function. ${ }^{6}$

Table 3 shows the estimation of our proxy variable for real time allocated to interactive activities, the degree of R\&D co-operation with firms. The significance of the $\mu$ parameter across all columns indicates that the dependent variable is actually ordered, thus the technique of estimation is adequate. According to the base model in Column 1, the frequency of R\&D cooperation depends positively on wage, knowledge contribution by unit of time allocated to interactive activities and weight given to interactive activities in the determination of prestige. This frequency does not depend on knowledge contribution by unit of time allocated to non-interactive activities. Frequency of co-operation depends negatively on income from interactive activities and parameters of the utility function. Note that the sign for wage and income from interactive activities is different from the predicted by the theoretical model. When we drop variable w (column 2), it can be observed an increase in significance of variable B since both are positively correlated. However, when we drop B in column 3, w shows higher significance than B in column 2. The estimation in column 3 is also a reduced model with significant variables only. Therefore, we consider that column 3 reflects better the rationale of our theoretical model.

In Table 4 we analyse marginal effects of the reduced models from Table 2 and Table 3 . For support, the scale factor is 0.91 , so marginal effects in column 1 do not make much difference with full effects from Table 2. On the contrary, for cooperation they permit the interpretation of the estimated coefficients as elasticities and clarify the direction of change. According to Column 2, marginal effects show that an increase of wage (w) rises the probability of "some cooperation" by $6 \%$ and of "much/very much cooperation" by $8 \%$. An increase of relative prestige from interaction $(\delta)$ rises the probability of "some cooperation" by $9 \%$ and of "much/very much cooperation" by $13 \%$. An increase of efficiency in the production of interactive knowledge (A) rises the probability of "some cooperation" by $34 \%$ and of "much/very much cooperation" by $51 \%$. An increase of revenue from interaction (Q) reduces the probability of "some cooperation" by $9 \%$ and of

\footnotetext{
${ }^{6}$ We also made estimations using ordinary least squares and ordered probit models -in this latter case, taking the integer part of the original variable to transform it into an ordinal one. It did not change the results.
} 
"much/very much cooperation" by $13 \%$. An increase of the preference for income instead of prestige (e) reduces the probability of "some cooperation" by $9 \%$ and of "much/very much cooperation" by $14 \%$.

\section{Conclusions}

We conclude that the relative weight given to interactive vs. non-interactive activities in the determination of prestige, measured through non-monetary incentives, is significant, whereas wage is less explicative and revenue from a unit of knowledge produced by interactive activities is not significant, i.e. monetary incentives, are not. This has one major implication: policies towards nonmonetary incentives are more difficult to implement and therefore promoting UII must be seen as a medium-long term target rather than a short-term one. ${ }^{7}$

Although less subject to public control, it is relevant to notice that the effect of knowledge contribution by unit of time allocated to non-interactive activities is significant, whereas it is not the case for interactive activities. This implies that UII is a question of how difficult is to produce non-interactive knowledge rather than how difficult is UII per se.

Our second conclusion is related to the possible existence of rationing, i.e. individual is unable to interact as much as desired since the real amount of interaction may be decided by industry. In this sense, we detect that the intensity of the support for the objectives of interaction and the degree of actual R\&D cooperation differ. However, there may be a (non-exclusive) explanation, from the econometric perspective, i.e. a misspecification problem given that industry's decision may affect the results. To disentangle this issue will be subject to further research ${ }^{8}$. It would be interesting because if UII is considered as desirable, policy initiatives might help to eliminate suboptimal situations arising from rationing.

These conclusions should only apply to regions like the one we have analysed, i.e. with low absorptive capacity. This can be seen either as a limitation or as an opportunity to study UII from a

${ }^{7}$ This is consequent with the long-standing idea from psychology that social reinforcement has greater influence on the determination of behaviour than material reinforcement (e.g. Bandura, 1977).

${ }^{8}$ This research should start by the theoretical analysis of firm's use of university R\&D, in the line of Cohen and Levinthal (1989), to end up with a general equilibrium model, following Gambardella and Hall (2005). 
less common perspective, not focused as usually on high-tech regions. In a high-tech region, we expect lower levels of rationing, so we may wonder that the estimation of optimum and real effort would show less differences, but of course this makes it convenient to test the model with a sample from such a region.

\section{Acknowledgements}

To Fragiskos Archontakis, Ignacio Fernández-de-Lucio and Antonio Gutiérrez-Gracia, for participation in former approaches to this research. To Pablo D'Este, for a deep revision of an earlier version. To Marian Pérez-Marín, for provision of references on psychology. To an anonymous referee, for useful comments. Remaining errors are only our responsibility.

\section{References}

Azagra-Caro, J., Archontakis, F., Fernández de Lucio, I., Gutiérrez Gracia, A., 2006. Faculty support for the objectives of university-industry relations versus degree of $R \& D$ cooperation: the importance of regional absorptive capacity. Research Policy 35: 37-55.

Baimbridge, M., Simpson, C., 1996. Rewards to academia: the remuneration of vice chancellors and principals. Applied Economics 28: 631-639.

Bandura, A. (1977): Social learning theory, Englewood Cliff, N. J.: Prentice-Hall.

Beath, J., R. Owen, J. Poyago-Theotoki, D. Ulph (2003): “Optimal Incentives for Income-Generation within Universities: The Rule of Thumb for the Compton Tax", International Journal of Industrial Organization 21: 1301-1322.

Bleaney, M., Binks, M. R., Greenaway, D., Reed, G. V., Whynes, D. K., 1992. What does a University add to its local economy? Applied Economics 24: 305-311.

Clark, B. R. (1998): Creating Entrepreneurial Universities, Guilford: IUA Press, Pergamon.

Cohen, W. M., Levinthal, D. A., 1989. Innovation and Learning: The Two Faces of R\&D. The Economic Journal 99: 569-596.

Cohen, W. M., D. A. Levinthal (1990): “Absorptive Capacity: a new Perspective on Learning and Innovation”, Administrative Science Quarterly 35 (1): 128-152.

Dasgupta, P. and P. David (1994): “Towards a new economics of science”, Research Policy 23 (5): 487-521. 
David, P., D. C. Mowery and E. W. Steinmueller (1994): “Analyzing the Economic Payoffs from Basic Research”, D. Mowery (ed.): Science and Technology Policies in Interdependent Economies, Boston: Kluwer, pp. 57-78.

Deaux, K., B. Major (1987): "Putting gender into context: an interactive model of gender-related behaviour", Psychological Bulletin 85: 85-116.

Etzkowitz, H. and L. Leydesdorff (1996): "Emergence of a Triple Helix of University-Industry-Government Relations", Science and Public Policy 23: 279-286.

Euwals, R., Ward, M. E., 2005. What matters most: teaching or research? Empirical evidence on the remuneration of British academics. Applied Economics 37 (14): 1655-1672.

Freeman, C. (1987): Technology Policy and Economic Performance: Lessons from Japan, London: Pinter.

Gambardella, A., Hall, B. H., 2005. Proprietary vs. Public Domain Licensing of Software and Research Products. NBER Working Paper No. 11120.

Gibbons, M., C. Limoges, H. Nowotny, S. Schwartzman, P. Scoot and M. Trow (1994): The New Production of Knowledge, Sage Publications.

Jensen, R., M. Thursby (2004): “The Academic Effects of Patentable Research", NBER Working Paper 10758

Lundvall, B. A. (1988): "Innovation as an interactive process: from user-producer interaction to the national system of innovation”, in G. Dosi, C. Freeman, R. Nelson, G. Silverberg and L. Soete (eds.): Technical Change and Economic Theory, Pinter: London.

Niosi, J., B. Bellon (2002): “The Absorptive Capacity of Regions”, Colloque Economie Méditerranée Monde Arabe, Sousse 20-21 September.

Pons, A., J. M. Blanco, 2005. Sheepskin effects in the Spanish labour market: a public-private sector analysis, Education Economics 13 (3): 331-347.

Salter, A. J. and B. R. Martin (2001): "The economic benefits of publicly funded basic research: a critical review”, Research Policy 30: 509-532.

Scott, A., G. Steyn, A. Geuna, S. Brusoni and E. W. Steinmueller (2002): The Economic Returns to Basic Research and the Benefits of University-Industry Relationships: A literature review and update of findings, SPRU: Report for the Office of Science and Technology.

\section{Appendix}

The survey included questions regarding the support for different objectives of UII, which we will use as a proxy for the optimum effort allocated to interactive activities. The basic assumption 
is that the higher support for the objectives of UII, the higher propensity to allocate time to interactive activities. Hence, we define:

Support: average importance given to six objectives of UII

To favour oriented research in the university

To participate in the economic development of the region

To intensify the commercialisation of the results of academic research

To favour the creation of firms based on academic research

To obtain additional funds for R\&D activities

To adapt teaching programmes ${ }^{9}$

Each objective was ranked as follows: 0 ("no or weak support"), 1 (“some support") and 2 ("strong support"). We assume that they have the same weight in the determination of their average. Support is therefore a quasi-continuous variable ranging between 0 and 2. Since we want the predictions of the model to fall between this range, we consider that support follows a distribution that is left-censored at 0 and right-censored at 2 . The tobit model appears to be the adequate method of estimation given this consideration.

The optimum effort allocated to interactive activities may not coincide with the degree of real interaction, i.e. if exogenous constraints or rationing on individual behaviour arises. It would result in a degree of real interaction below the individual optimum. Consequently, we define another variable as a proxy for the real effort allocated to interactive activities:

* Cooperation: perceived degree of R\&D cooperation with firms. We considered three answers, ranked as follows: 0 (“none”), 1 ("some”) and 2 (“much" or "very much").

Given the qualitative and indexed nature of the response variables for cooperation we decided to use an ordered probit for estimating our econometric model.

Here is the list and description of the explanatory variables:

* w: proxy for faculty wage. It is the average of the following variables, ranging from 0 to $3^{10}$ :

Age: 0 (less than 30 years), 1 (30-39 years), 2 (40-49 years), 3 (more than 49 years).

\footnotetext{
${ }^{9}$ For a separate treatment of each objective, see Azagra et al (2006).

${ }^{10}$ We also tried to build an alternative variable for wage, $\mathrm{w}^{\mathrm{e}}$, according to this formula (Pons and Blanco, 2005): $\mathrm{w}^{\mathrm{e}}=\exp \left[6.4738+0.0248 *(\right.$ faculty age $)-0.0003 *\left(\right.$ faculty age $\left.{ }^{2}\right)+0.0048 *($ years of teaching experience $)+0.1504 *($ teaching scale $)]$. It did not change the results.
} 
Teaching experience: 0 (less than 5 years), 1 (5-9 years), 2 (10-14 years), 3 (more than 14 years).

Teaching scale: 0 (associate professor), 1 (assistant professor), 2 (full professor 1), 3 (full professor 2). ${ }^{11}$

Number of Spanish six-year term research awards (so-called sexenia): 0 (none), 1 (one), 2 (two), 3 (more than two).

Holding a managerial position at the university: 0 (no), 3 (yes). ${ }^{12}$

* Q: proxy for net revenue from a unit of knowledge produced by interactive activities. It is the average of the following variables, regarding the perceived influence of UII on some aspects of academic life. All take values 1 (positive) or 0 (otherwise):

Perceived influence of UII on faculty members salary

Perceived influence of UII on public resources for R\&D projects

Perceived influence of UII on scientific career (sexenia)

* $\delta$ : proxy for the relative weight given to interactive vs. non-interactive activities in the determination of prestige. It is the average of the following variables, with the same interpretation and range of those included in $\mathrm{w}$ :

Perceived influence of UII on professional openings for students and collaborators

Perceived influence of UII on exchange of relevant knowledge

Perceived influence of UII on freedom of selection of research agenda

* A: proxy for knowledge contribution by unit of time allocated to interactive activities. It is the average of the following variables, ranging from 0 to 1 :

> Technological content of faculty members' university: 0 (four non-polytechnic universities), 1 (one polytechnic university).

> Technological content of faculty members' discipline: 0 (social sciences and humanities), 0.5 (exact and natural sciences), 1 (engineering and technology).

${ }^{11}$ Some full professors in Spain are hired only for teaching. This is what we call "full professors 1". The rest have also time for research activities. This is what we call "full professors 2".

${ }^{12}$ On the relationship between managerial positions within university and wage, see Baimbridge and Simpson (1996). 
Being an associate professor: 0 (no), 1 (yes). The rationale under this variable is that associate professors in Spain are supposed to have previous experience in non-academic domains, e.g. industry.

Length of research abroad: 0 ( 0 months), 0.25 (between 0 and 5 months), 0.5 (between 6 and 24 months), 1 (more than 24 months). Here the assumption is that faculty members who do research abroad do so to improve their scientific skills. Hence, they will tend to travel to leading scientific countries with more to offer, especially if they are from regions with low absorptive capacity. Some of these leading countries also interact more with industry.

Perceived influence of the institutional policy of the respondent's university on cooperation with firms: 1 (“it favours cooperation"), 0 (otherwise).

B: proxy for knowledge contribution by unit of time allocated to non-interactive activities. It is the average of the following variables, ranging from 0 to 3 :

Faculty member's university age: 0 (two ten years old universities), 1 (a twenty years old university), 2 (a thirty-five years old university), 3 (a five hundred years old university).

Teaching experience: same as defined for $\mathrm{w}$.

* e: personal preferences in the utility function. We assume that they may vary according to gender, although we are limited to use a rough measure of gender -sex: 0 (male), 1 (female) ${ }^{13}$.

Table 1 offers descriptive statistics of the independent variables. Notice that the highest correlation corresponds to $\mathrm{w}$ and $\mathrm{B}$, so we will have to consider it in the estimations.

${ }^{13}$ The idea that gender differences may influence preferences is widely accepted by psychologists (e.g. Deaux and Major, 1987). 


\section{Tables}

Table 1. Descriptive statistics of independent variables

\begin{tabular}{|c|c|c|c|c|c|c|c|c|c|}
\hline \multirow[t]{2}{*}{ Variable } & \multirow[t]{2}{*}{ Mean } & \multirow{2}{*}{$\begin{array}{l}\text { Standard } \\
\text { deviation }\end{array}$} & \multirow{2}{*}{$\begin{array}{l}\text { Number } \\
\text { of cases }\end{array}$} & \multicolumn{6}{|c|}{ Correlation matrix } \\
\hline & & & & $\mathrm{W}$ & Q & $\delta$ & A & B & $\mathrm{E}$ \\
\hline $\mathrm{w}$ & 1.23 & 0.80 & 357 & 1.00 & & & & & \\
\hline $\mathrm{Q}$ & 0.51 & 0.31 & 380 & 0.06 & 1.00 & & & & \\
\hline$\delta$ & 0.63 & 0.29 & 380 & -0.04 & 0.44 & 1.00 & & & \\
\hline $\mathrm{A}$ & 0.39 & 0.20 & 367 & -0.05 & 0.12 & 0.22 & 1.00 & & \\
\hline B & 1.70 & 0.90 & 378 & 0.67 & -0.03 & -0.08 & -0.06 & 1.00 & \\
\hline $\mathrm{e}$ & 0.28 & 0.45 & 380 & -0.01 & -0.07 & -0.05 & -0.18 & 0.08 & 1.00 \\
\hline
\end{tabular}

Table 2. Tobit estimation of optimum time allocated to interactive activities (support) - censored $(0,2)$

\begin{tabular}{|c|c|c|c|c|}
\hline & $\begin{array}{l}1 \\
\text { Base model }\end{array}$ & $\begin{array}{l}2 \\
\text { w not included }\end{array}$ & $\begin{array}{l}3 \\
\text { B not included }\end{array}$ & $\begin{array}{l}4 \\
\text { Reduced model }\end{array}$ \\
\hline Number of observations & 328 & 346 & 328 & 358 \\
\hline \multirow[t]{2}{*}{ Log likelihood function } & -274.33 & -295.37 & -275.32 & -308.01 \\
\hline & Coeff. (t-ratio) & Coeff. (t-ratio) & Coeff. (t-ratio) & Coeff. (t-ratio) \\
\hline Constant & $0.22(0.72)$ & $0.12(0.38)$ & $0.15(0.48)$ & $0.93(9.66)$ \\
\hline $\mathrm{w}$ & $-0.03(-0.61)$ & & $-0.08(-2.12)$ & \\
\hline $\mathrm{Q}$ & $0.13(1.21)$ & $0.12(1.12)$ & $0.14(1.32)$ & \\
\hline$\delta$ & $0.61(5.23)$ & $0.66(5.6)$ & $0.62(5.26)$ & $0.7(6.55)$ \\
\hline $\bar{A}$ & $0.03(0.19)$ & $0.06(0.41)$ & $0.03(0.17)$ & \\
\hline $\mathrm{B}$ & $-0.06(-1.41)$ & $-0.09(-2.62)$ & & $-0.09(-2.76)$ \\
\hline $\mathrm{e}$ & $-0.02(-0.24)$ & $-0.01(-0.07)$ & $-0.03(-0.38)$ & \\
\hline$\sigma$ & $0.53(23.27)$ & $0.54(23.62)$ & $0.53(23.27)$ & $0.54(24.11)$ \\
\hline
\end{tabular}


Applied Economics submission - after $1^{\text {st }}$ revision

Table 3. Ordered probit estimation of real time allocated to interactive activities (cooperation)

\begin{tabular}{llll}
\hline & 1 & 2 & 3 \\
& Base model & w not included & B not included (reduced model) \\
\hline Number of observations & 340 & 359 & 340 \\
\hline Log likelihood function & -313.70 & -339.92 & -313.71 \\
\hline Prob $\left[\chi^{2}>\right.$ value $]=$ & 0.00 & 0.00 & 0.00 \\
\hline \multicolumn{4}{l}{} \\
\hline Constant & Coeff. (t-ratio) & Coeff. (t-ratio) & Coeff. (t-ratio) \\
\hline W & $-2.92(-4.35)$ & $-2.34(-3.66)$ & $-2.94(-4.44)$ \\
\hline Q & $0.36(3.3)$ & & $0.35(4.3)$ \\
\hline$\delta$ & $-0.57(-2.45)$ & $-0.47(-2.12)$ & $-0.56(-2.44)$ \\
\hline A & $0.53(2.06)$ & $0.51(2.04)$ & $0.53(2.07)$ \\
\hline B & $2.14(6.15)$ & $1.9(5.74)$ & $2.14(6.15)$ \\
\hline $\mathrm{e}$ & $-0.02(-0.19)$ & $0.17(2.46)$ & \\
\hline$\mu$ & $-0.58(-3.83)$ & $-0.62(-4.25)$ & $-0.59(-3.85)$ \\
\hline & $1.11(12.39)$ & $1.1(12.88)$ & $1.11(12.39)$ \\
\hline
\end{tabular}

Table 4. Marginal effects of the estimation of optimum and real time allocated to interactive activities

\begin{tabular}{lllll}
\hline & 1 & & \\
& Tobit Model - censored $(0,2)$ & Ordered Probability Model & \\
\hline Dependent variable & Support & Cooperation & & \\
\hline & Coeff. & Cooperation $=0$ & Cooperation $=1$ & Cooperation=2 \\
\hline Constant & 0.84 & 0.00 & 0.00 & 0.00 \\
\hline $\mathrm{w}$ & & -0.14 & 0.06 & 0.08 \\
\hline $\mathrm{Q}$ & & 0.22 & -0.09 & -0.13 \\
\hline$\delta$ & 0.64 & -0.21 & 0.09 & 0.13 \\
\hline $\mathrm{A}$ & & -0.85 & 0.34 & 0.51 \\
\hline $\mathrm{B}$ & -0.08 & & & -0.12 \\
\hline $\mathrm{e}$ & & 0.23 & -0.11 & \\
\hline
\end{tabular}

